Brit. J. vener. Dis. (1960), 36, 14.

\title{
PRESENT STATUS OF THE MANAGEMENT OF CARDIOVASCULAR SYPHILIS*
}

\author{
BY \\ BRUCE WEBSTER \\ From the Department of Medicine of Cornell University and the New York Hospital, New York
}

\begin{abstract}
Although there is very little that is new or dramatic to report in the field of cardiovascular syphilis, it is perhaps advisable to evaluate the situation at this time in order to remind ourselves that this condition still exists, and that it is a clinical and public health problem.
\end{abstract}

\section{INCIDENCE}

For various reasons, it is impossible to obtain an exact estimate of the incidence of involvement of the cardiovascular apparatus in patients with syphilis. To some extent this is due to the difficulties of diagnosing syphilitic aortitis and of differentiating between syphilitic and rheumatic aortic insufficiency, and between syphilitic and arteriosclerotic aneurysm.

Much of the statistical information which is available on this subject is valueless from a clinical viewpoint, because authors have tended to discuss cardiovascular syphilis as an entity, grouping together aortitis, aortic insufficiency, and aneurysm, although the clinical signs, the symptomatology, and the prognoses are vastly different.

Although invasion of the aorta probably occurs during the initial stage of spirochaetaemia, and living spirochaetes have been demonstrated in the aortic wall, clinical recognition of the disease does not usually occur until 15 to 20 years later. Why the aorta, more than other arteries, bears the brunt of the burden of this infection has not been satisfactorily explained. There is evidence from several sources (Bruusgaard, 1929; Turner, 1930) that, if untreated, 10 per cent. of all cases of early syphilis will develop some form of cardiovascular involvement.

Beginning with the early papers of Moore (1941) and Grant (1933), there has been, until recently, apparently undisputed evidence that the adequate treatment of primary, secondary, or latent syphilis would completely prevent the occurrence of cardiovascular manifestations. Within the past few years, however, isolated reports have appeared suggesting the development of these lesions in seemingly adequately treated cases. A critical review of such

Paper read at M.S.S.V.D.-I.U.V.D.T. meeting in London, October 16, 1959. reports (Barnett, 1955) reveals that almost all the cases concerned had been treated at a late stage of the disease. If one takes cognizance of the difficulties encountered in the early diagnosis of uncomplicated aortitis, it would seem highly probable that the aorta was already damaged when treatment was first given and that a weakened fibrotic aortic wall suffered further damage, probably through arteriosclerosis or hypertension and then produced readily recognizable physical signs. Re-infection may also have been a factor in some of these cases. There is, I believe, adequate evidence to indicate that specific treatment of early syphilis will prevent completely the development of cardiovascular lesions, and this is thus the only form of heart disease which is completely preventable. Surely this represents a challenge to continue our efforts in the epidemiological control of early and latent syphilis.

That aneurysm, and to a lesser extent, syphilitic aortic insufficiency, is less frequent to-day than it was 50 years ago, is a commonly held and correct opinion. The extent of this decrease in incidence varies widely in different parts of the world, in direct proportion to the degree of control of early syphilis and the time period during which that control has been in force. There may well be a 20 -year difference in the decrease in early and cardiovascular syphilis. There is available considerable information as to the extent of this decrease in incidence. White (1944) has stated that it amounted to 50 per cent. in New England between 1928 and 1948. In Philadelphia, Welty (1939) found that in 1927-30 the incidence of cardiovascular syphilis seen at autopsy was one in every eleven autopsies, while in 1935-37 it was only one in every eighteen autopsies. In Texas, in a comparable series of hospital and clinic admissions for cardiac disease, the incidence of syphilis as an aetiological agent fell from $19 \cdot 3$ per cent. in 1927 to 12.7 per cent. in 1931 and to $2 \cdot 3$ per cent. in 1953 (Hutcheson, Hejtmancik, and Herrmann, 1953). This is especially significant since it occurred in an area with a large Negro population, in which the incidence is usually high. In Los Angeles County, syphilitic heart disease comprised 
0.32 per cent. of all hospital admissions in 1946-47 and only 0.17 per cent. in 1953-54 (Rimsa and Griffith, 1957).

It is worthy of note that it was not until 1937 that active organized nation-wide efforts towards the control of early syphilis were begun in the U.S.A. This effort reached its peak in 1948 when the incidence of infectious syphilis fell off sharply. Perhaps the present marked decrease in cardiovascular syphilis represents the result of the beginning of this campaign. If so, more striking results may be expected during the next 10 to 15 years.

\section{Aetiology}

Certain factors apparently play a role in determining whether or not an individual with syphilis will become one of the 10 per cent. who develop cardiovascular involvement. Osler (1892) wrote as follows:

"I was struck with the frequency with which aortic insufficiency occurs in soldiers at the Philadelphia Hospital, to which many veterans of the Civil War are admitted. The majority of these cases had worshipped at the shrines of Bacchus and Vulcan-and not a few at that of Venus."

With modifications this concept is still true. Males develop cardiovascular syphilis approximately six times as frequently as females, and this is probably due to the higher incidence of the disease in the male.

Much has been written concerning the specific vulnerability of the Negro race to develop cardiovascular syphilis. There is no proof that the higher incidence of such cardiac lesions in this race is not a direct reflection of the high incidence of neglected early syphilis in the same group.

The relationship of hard manual work to the development of cardiovascular syphilis has not been established. However, once some form of the disease has developed, hard work can play a major role in the determination of life expectancy.

Let us consider for a moment the 90 per cent. of infected, untreated individuals who do not develop cardiovascular syphilis. Do they possess or develop some natural immunity which protects them? Such a possibility is feasible. With the development of the treponemal immobilization test and similar measures of true immunity, we have available now the tools for such a study.

It has long been held that certain countries and races, although having a high incidence of early and latent syphilis, have very few cases of cardiovascular syphilis. Various observers have remarked upon this in Arabia, Japan, and the island of Bermuda. Although without statistical corroboration, this clinical impression may well represent some degree of racial or national immunity. Investigation along this line is possible.

Another set of factors influence the natural history of cardiovascular syphilis, once it has developed. It is now conceded that specific antisyphilitic therapy should be given as soon as the diagnosis has been established, provided such treatment has not been given in the past. However, the evaluation of the effect of such therapy is extremely difficult. An attempt to do this in a co-operative study of 1,000 cases of syphilitic aortic insufficiency at the Johns Hopkins Hospital and the New York Hospital brought to light so many variables that it was impossible to reach a statistically sound conclusion (Webster, Rich, Densen, Moore, Nicol, and Padget, 1953). However, the clinical impression first suggested by Moore (1941), that adequate treatment at the time of diagnosis lessens symptoms and prolongs life, still stands. There is pathological evidence that such treatment eradicates the evidence of an active syphilitic process in the aorta, replacing it with scar tissue.

The question always arises whether the aortic insufficiency is due to syphilis or to rheumatic endocarditis, bacterial endocarditis, arteriosclerosis, or calcifying disease. Many previous writers confuse this issue by referring to the incidence of syphilitic aortic insufficiency with a negative serological test for syphilis, without discussing whether or not these cases had a history of syphilis or had received antisyphilitic therapy. McDermott, Tompsett, and Webster (1942) were able to obtain a positive STS or a history of syphilis or treatment in 98 per cent. of a series of 135 cases of aortic insufficiency. In 141 cases of uncomplicated aortitis reported by Rich and Webster (1952), positive STS were observed in 125 individuals. The remaining sixteen gave a history of syphilis or treatment. The development of the treponemal immobilization test has provided an agent whereby this ogre of syphilitic heart disease without evidence or history of syphilis can be permanently disposed of. The studies of Friedman and Olansky (1955) have demonstrated the use to which the treponemal immobilization test can be put in determining the aetiological agent in such cases.

\section{Prognosis}

Uncomplicated Aortitis.-There is evidence that, if adequately treated, this does not greatly alter the life expectancy of the individual. This is a strong argument for redoubling our efforts to discover more 
cases of cardiovascular syphilis in this stage of the disease. The careful examination of every case of late syphilis, together with the use of fluoroscopy, left lateral oblique films, and, in selected cases, angiocardiography, will accomplish this end. By so doing, we can prevent the development of the later, more disabling forms of the disease.

The coincidental development of arteriosclerosis or hypertension alters, for the worse, the prognosis of cardiovascular syphilis.

In spite of all this, the prognosis of all forms of the disease, with the exception of aneurysm, is infinitely better than has been formerly stated.

Aortic Insufficiency. - Although admittedly the prognosis in syphilitic aortic insufficiency is not as good as in uncomplicated aortitis, the diagnosis is much more readily made from the definite physical signs. 1,020 cases from the Johns Hopkins Hospital and the New York Hospital were analysed with a view to determining the natural history of this disease (Webster and others, 1953). In this series, approximately 25 per cent. of the patients survived for 15 years and 38 per cent. survived 10 years after diagnosis. This survival is to some extent dependent on certain factors inherent in the patient. The age at the time of diagnosis is apparently not very important. Race and sex influences were difficult to evaluate because of the many factors involved. Whereas manual work has long been considered to be a factor in the production of this disease, it did not seem in our series to have much effect until the disease was established. Only half of the patients with syphilitic aortic insufficiency in this study had symptoms at the time of diagnosis. This fact is important in prognosis; 51 per cent. of those who were symptom-free at diagnosis survived for 10 years, as against 29 per cent. of those who had symptoms. The onset of congestive heart failure influences prognosis adversely; 32 per cent. of those without symptoms of heart failure survived for 10 years, as against 6 per cent. of those who had such symptoms. The development of angina, although a serious complication, did not in itself influence survival to a great extent.

Subacute Bacterial Endocarditis.-12 per cent. of the cases of aortic insufficiency reported by Grant (1933) developed subacute bacterial endocarditis. Some of these were in the syphilitic group but the exact number is difficult to determine. During recent years evidence has been accumulated that bacterial endocarditis occurs in pure syphilitic aortic insufficiency much more frequently than was formerly supposed.
Aneurysm.-This represents a late stage of cardiovascular syphilis which is becoming increasingly rare. Angiocardiography has been of great value in the early detection of aneurysms. The treponemal immobilization test best enables us to differentiate between arteriosclerotic and syphilitic aneurysms, and the radiologists have also shown increased interest in the differential diagnosis of these two types of aneurysm.

Recently the vascular surgeon has been a great help in the management of these cases, but there has been a tendency to attempt the surgical repair of aneurysms which would better be left alone. If adequate specific therapy has been given when the aneurysm is still fusiform or in the early saccular stage, the majority of the patients will do well unless they develop hypertension or extensive arterial changes due to arteriosclerosis. If either of these changes occur, expansion may take place. It has been our experience that evidence of expansion after adequate antisyphilitic treatment is an indication for surgery, but this is a dangerous undertaking with only a fair prognosis at best and the probable results must be evaluated in terms of the life expectancy if the aneurysms were left alone. Successful surgical repair of ruptured aneurysm has been reported.

Coronary Ostial Stenosis. - Syphilitic coronary ostial stenosis which is sufficiently serious to cause clinical symptoms or electrocardiographic changes is surprisingly very rare.

\section{Treatment of Cardiovascular Syphilis}

The most effective treatment of cardiovascular syphilis is its prevention by the adequate treatment of early or latent syphilis, and its complete eradication depends on this factor alone.

The aim of treatment is to bring about healing of the tissue which has been damaged by active inflammation and its replacement with fibrous connective tissue.

There are two basic components in the treatment of cardiovascular syphilis. One is the overall general management of the patient's cardiac status, which includes adjustment of his living conditions and his workload, the administration of digitalis and diuretics, if necessary, and all the other factors which constitute good management of any form of heart disease. The other is the specific antibiotic treatment, aimed at the healing of the inflammatory process in the aorta. 6 to 10 million units of penicillin over a 2- to 3-week period would seem to be the accepted dosage. Tetracyclines have been used in cases of penicillin sensitivity. 
The effect of specific treatment on the outcome of cardiovascular syphilis is impossible to evaluate. The symptoms, particularly pain, appear to decrease. There is pathological evidence that the inflammatory process in the aorta is replaced by a fibrosis. The life expectancy is increased, but it is questionable whether this is due to better cardiac management or to specific therapy.

\section{SUMMARY}

Cardiovascular syphilis is still a public health and a clinical problem. There is conclusive evidence that the incidence is decreasing rapidly, and it would seem that this decrease is a direct result of improved methods of control and treatment of early syphilis. A lag of 10 to 20 years between the decrease in early syphilis and that in cardiovascular manifestations of the disease is to be expected. This decrease will continue only if we persist in our efforts in case-finding and in the control of early syphilis. Further efforts should be made to detect cardiovascular syphilis while it is still at the stage of uncomplicated aortitis. This can best be done by careful physical examinations, chest radiography, and perhaps angiocardiography, in all cases of late and latent syphilis. Although modern laboratory techniques, such as angiocardiography, are of great value in the early diagnosis of cardiovascular syphilis, a careful physical examination by a physician adequately trained in physical diagnosis, augmented perhaps by a fluoroscopic examination, must still be the chief method for the early detection of this condition.

There is increasing evidence that specific antisyphilitic treatment with penicillin and good cardiac management will bring about a healing of the active process in the aorta with consequent prolongation of life. However, before the condition can be treated, it must be detected.

It is also most important to remember that the best form of treatment of cardiovascular syphilis is its prevention by early case-finding and by the adequate treatment with antibiotics of primary, secondary, or latent syphilis.

All these factors suggest that within the not too distant future we shall have in our hands the power to eradicate this once major form of cardiac disability.
REFERENCES

Barnett, C. W. (1955). Stanford med. Bull., San Francisco, 13, 234.

Bruusgaard, E. (1929). Arch. Derm. Syph. (Berl.), 157, 309

Friedman, B , and Olansky, S. (1955) Amer. Heart J., 50, 323

Grant, R. T. (1933). Heart, 16, 275 .

Hutcheson, J. M., Hejtmancik, M. R., and Herrmann, G. R. (1953). Amer. Heart J., 46, 565 .

McDermott, W., Tompsett, R. R., and Webster, B. (1942). Amer. J. med. Sci., 203, 202.

Moore, J. E. (1941a). "The modern Treatment of Syphilis", 2nd. ed., p. 285. Thomas, Baltimore.

(1941b). Ihid., p. 290

Osler W. (1892). "The Principles and Practice of Medicine", p. 603. Appleton, New York.

Rich, C., and Webster, B. (1952). Amer. Heart J., 43, 321.

Rimsa, A., and Griffith, G. C. (1957). Ann. intern. Med., 46, 915.

Turner, T. B. (1930). Bull. Johns Hopk. Hosp., 46, 159.

Webster, B., Rich, C., Densen, P. M., Moore, J. E., Nicol, C. S., and Padget, P. (1953). Amer. Heart J., 46, 117.

Welty, J. W. (1939). Amer. J. med. Sci., 197, 782.

White, P. D. (1944). "Heart Disease", 3rd ed., p. 375. Macmillan, New York.

L'état actuel de la lutte contre la syphilis cardiovasculaire Résumé

La syphilis cardiovasculaire demeure un problème clinique et de santé publique. On a des preuves concluantes que sa fréquence diminue rapidement et il semble que cette diminution est due directement aux meilleures méthodes de contrôle et de traitement de la syphilis précoce. On devrait s'attendre à un intervalle de 10 à 20 ans entre la réduction de la syphilis précoce et celle des manifestations cardiovasculaires. La persistance de cette réduction dépendra de la continuité de nos efforts pour dépister et traiter la syphilis précoce. On s'efforcera particulièrement de déceler la syphilis cardiovasculaire déjà à la période d'aortite non-compliquée. On peut achever cela par un examen clinique soigneux, par une radiographie thoracique et, peut-être, par une angiocardiographie dans tous les cas de syphilis tertiaire et latente. Bien que des procédés modernes de laboratoire, tels qu'angiocardiographie, soient très importants pour reconnaître de bonne heure la syphilis cardiovasculaire, un examen soigneux par un médecin bien instruit en méthodes de diagnostic par les sens, renforcé peut-être par une radioscopie, demeurera le moyen principal du diagnostic précoce.

Un nombre croissant de preuves montre, qu'un traitement anti-syphilitique spécifique par la pénicilline et une bonne thérapie cardiaque effectueront la guérison du processus morbide aortique, prolongeant ainsi la vie. Toutefois, pour traiter l'affection, il faut bien l'avoir trouvé.

Il est aussi important de ne pas oublier que la meilleure manière de traiter la syphilis cardiovasculaire est de la prévenir, en la dépistant et traitant par des antibiotiques la syphilis primaire, secondaire et latente.

Tous ces facteurs nous permettent d'espérer que dans un avenir peu éloigné nous aurons le pouvoir d'extirper cette forme, autrefois majeure, d'affection cardiaque. 